\title{
Flore au paradis. Emblématique et vie religieuse au XVI et XVII siècles, présentation de Paulette Choné et Bénédicte Gaulard, Glasgow
}

\section{Michele Mastroianni}

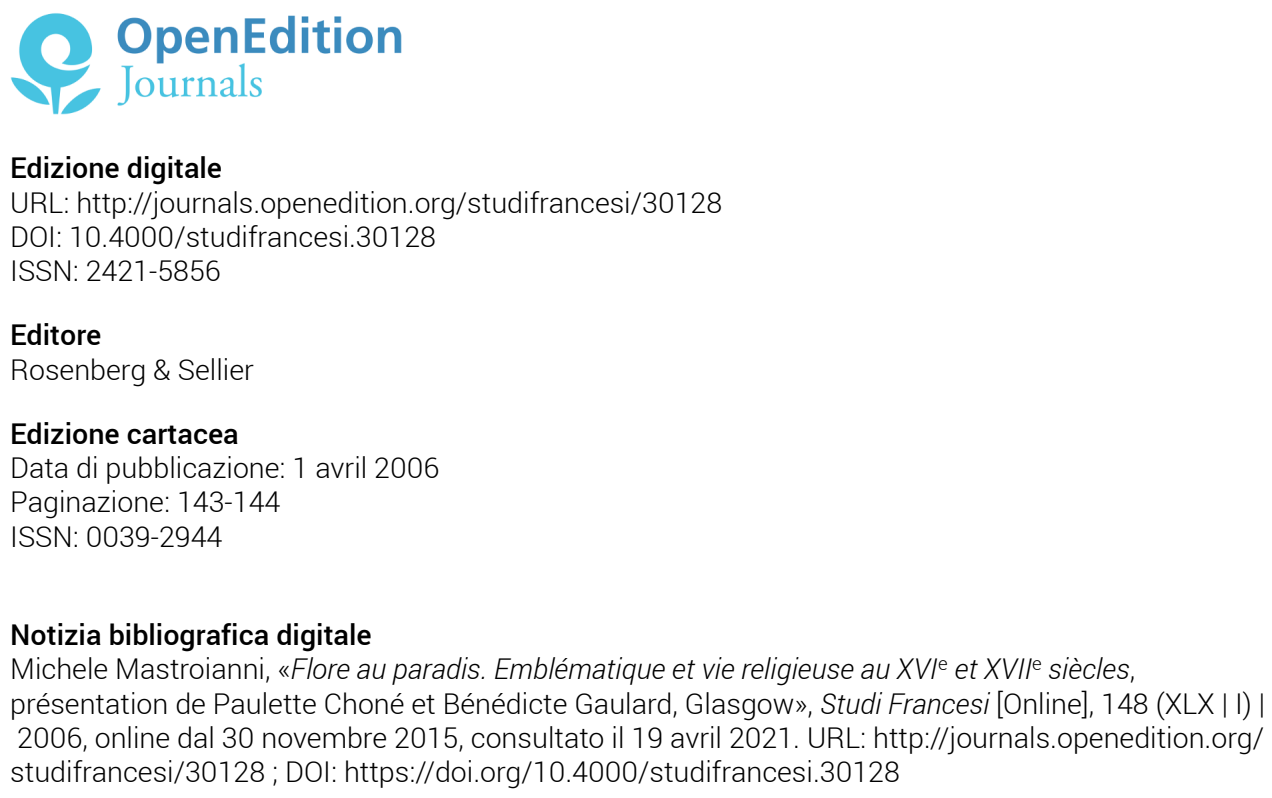

Questo documento è stato generato automaticamente il 19 avril 2021.

\section{(ब) $\odot \Theta \Theta$}

Studi Francesi è distribuita con Licenza Creative Commons Attribuzione - Non commerciale - Non opere derivate 4.0 Internazionale. 


\title{
Flore au paradis. Emblématique et vie religieuse au XVI et $X V I I^{\mathrm{e}}$ siècles, présentation de Paulette Choné et Bénédicte Gaulard, Glasgow
}

\author{
Michele Mastroianni
}

\section{NOTIZIA}

Flore au paradis. Emblématique et vie religieuse au XVI et XVII siècles, présentation de PAULETTE CHONÉ et BÉNÉDICTE GAULARD, Glasgow, «Glasgow Emblem Studies», vol. 9, 2004, pp. VIII+230.

Nei Glasgow Emblem Studies, di cui è responsabile Alison Adams, una delle maggiori specialiste degli studi attuali sull'emblematica e animatrice di una scuola vivace in questo campo, escono gli Atti di un convegno internazionele tenuto a Digione nel novembre $2002 \mathrm{su}$ emblemi ed immaginario floreale in rapporto con la vita religiosa e la spiritualità del Cinque e Seicento. L'ambito di indagine non concerne solo la Francia, ma anche l'Italia e la Spagna: il volume offre tuttavia un panorama utilissimo per il francesista, dato lo stretto intrecciarsi e interagire nella spiritualità controriformista (oggetto precipuo delle presenti ricerche) di componenti che vanno sempre al di là dei confini nazionali. L'emblema, come sottolinea Paulette Choné, serve da prezioso strumento nel ricostruire le relazioni tra l'espressione figurata della spiritualità $\mathrm{e}$ alcune pratiche religiose, offrendo appunto la possibilità di mettere in luce le convergenze che esistono tra l'universo devozionale e spirituale (a vari livelli: nella letteratura, nella liturgia, nelle arti sacre) e l'emblematica. Ora, «l'universo vegetale occupa un posto particolare negli emblemi, da quando Alciato ha introdotto nei suoi Emblemata una serie d'alberi e d'arbusti. [...] Ma molto al di là dell'eredità tradizionale $\mathrm{e}$ dei significati convenuti che apparentano talvolta il simbolismo floreale alla chiave dei sogni e all'astrologia popolare, l'emblematica sembra aver cercato di prendere, 
attraverso i motivi botanici, una distanza erudita nei confronti di un vocabolario simbolico minacciato di usura. [...] L'universo dei fiori offre un osservatorio privilegiato per apprezzare la sottigliezza dei 'passaggi' tra emblematica profana ed emblematica sacra, tra botanica e spiritualità, tra scienza e religione. [...] Il sussistere di una sensibilità decisamente ovidiana al tema della metamorfosi, il ricordo delle 'ragioni degli Antichi' negli usi trionfali, conviviali e funerari dei mazzi, ghirlande e piogge di fiori, l'interesse per le 'piante della Bibbia', la sacralizzazione metaforica della materia medica, in piena rivoluzione scientifica, testimoniano la complessità delle rappresentazioni e delle teorie che collegano la botanica, la storia, la poesia nell'epoca qui studiata, che è ancora quella dell'unità del mondo sotto lo sguardo di Dio, anche se tutti non leggono più concordemente nel 'gran libro della natura'» (pp. VI-VII).

Nella prima sezione, Les jardins symboliques: exégèse et histoire (V. ORTEGA-TILLIER, Palmier, figuier, arbres au fruit défendu. Remarques sur la représentation de la flore édénique, pp. 3-11; CL.-F. BRUNon, Du potager au Paradis: le jardin symbolique de Giulio Cesare Capaccio, pp. 13-35; J. LOACH, Le jardin céleste de Racconigi: la conception et l'usage d'un jardin d'apparence laïque de la Contre-Réforme, pp. 37-48), viene posto l'accento sull'immaginario dei giardini, da quello dell'Eden all'orticultura simbolica, sia che si tratti di una costruzione concettuale come nel trattato Delle imprese di Capaccio (1592) sia che si tratti di una costruzione materiale come nella dimora sabauda di Racconigi. Nella seconda sezione, La flore et l'expérience religieuse: itinéraires (B. G AULARD, «Flora et Borgogna». Peinture, spiritualité et mystique en Franche-Comté au XVII siècle, pp. 51-59; E. MONTANER, Les images végétales dans les emblèmes consacrés à la Vierge Marie, pp. 61-79; $\mathrm{CH}_{\mathrm{H}}$. Bouzy, Dites-le avec des emblèmes: mythes, symboles et botanique dans les Lettres espagnoles au Siècle d'Or, pp. 81-96; R. DEKONINCK, «Chercher et trouver Dieu en toutes choses»: méditation et contemplation florale jésuite, pp. 97-110), sono evocati parecchi centri della Riforma cattolica, attraverso il legame delle loro realizzazioni artistiche con l'emblematica. La terza sezione, Les emblèmes floraux: interprétations (A. R OLET, La pluie de fleurs dans les «Symbolicae Quaestiones» d'Achille Bocchi, entre spiritualité religieuse et éloquence encomiastique, pp. 113-151; F. Quiviger, Fleurs éparpillées dans deux tableaux du «Cinquecento» vénitien. Essai d'iconographie olfactive, pp. 153-167; V. HAYAERT, La fleur de Rhododaphné et le péril de l'exégèse biblique selon Pierre Coustau, pp. 169-194; S. ROLET, Une«Hieroglyphicomachia» végétale: la succession des papes Léon X, Adrien VI et Clément VII dans les«Hieroglyphica» de Pierio Valeriano, pp. 195-207; P. Choné, La prière de l'héliotrope, pp. 209-230), è consacrata all'ermeneutica propriamente detta di motivi floreali, a livello di espressione letteraria e di arti figurative. 